\title{
Abordagens alternativas no controle da esquistossomose: buscando incluir o subjetivo na epidemiologia
}

\author{
Alternative approaches to the control of \\ schistosomiasis: trying to include subjective \\ elements in epidemiology
}

Pedro Coura-Filho 1

\footnotetext{
1 Laboratório de Esquistossomose, Centro de Pesquisas René Rachou, Fundação Oswaldo Cruz. Av. Augusto de Lima 1715, C.P. 1743, Belo Horizonte, MG, 30190-002, Brasil.
}

Resumo Neste estudo é discutida a possi bilidade da incl usão do “subjetivo" na epi demi ologia. São apontadas abordagens alternati vas de se trabal har com programas de intervenção em populações carentes obj eti vando prestação de servi ços em educação, saúde e outros ti dos como obrigação do Estado e direi to do cidadão. São apontadas características da pesquisa participante, da "epi demi ologia comunitária" e da educação popular visando à construção de um modelo de controle da esquistossomose com opções metodológi cas alternati vas, incluindo as representações, percepções e modo de vi da de populações expostas à infecção pelo Schistosoma mansoni. É ainda apontado o Estado como responsável pela provisão de condições materiais, sem as quais não se forma ci dadões com consciência coletiva tão necessária na solução de problemas como a esquistossomose.

Palavras-chave Esquistossomose; Epidemiologia; Controle; SaúdePública

Abstract This study discusses the possibility of integrating the "subjective" in epidemiological research. Alternative approaches are presented for programs to provide health and educational services, as well as others which are the right of citizens to receive and the responsi bility of the government to provide. The characteristics of parti ci patory research, community-based epi demiology, and popular education programs are described, with the purpose of constructing a model for the control of schistosomiasis using alternative methodologies, including in the model the perceptions and life styles of populati ons exposed to Schistosoma mansoni. The Federal Government is indicated as the institution to provide the material conditions necessary to form a citizenry with the collective will to control schistosomiasis.

Key words Schistosomiasis; Epidemiology; Control; Public Health 
Introdução

Embora a OMS (1985) tenha preconizado a educação para a saúde e a participação comunitária como estratégia operacional no controle da endemia, no Brasil poucas são as experiências em que a população tenha participado ativamente de ações de controle da endemia (Barbosa et al., 1971; Barreto \& Prata, 1969; Coura-Filho et al., 1992). Não se têm muitas notícias de programas municipalizados com participação ativa da comunidade, nos quais o indivíduo torna-se objeto e sujeito do processo de transmissão e controle da endemia. Sabidamente, o Programa Especial de Controle da Esquistossomose (PECE, 1976), desenvolvido no nordeste do Brasil, deixou de ser um programa com medidas associadas (tratamento, controle de vetores, saneamento básico e educação sanitária com participação da comunidade), como proposto inicialmente. Caracterizou-se como um projeto de intervenção vertical (comunidade como objeto, decisões sobre a metodologia tomadas no nível de poder central, atividades executadas por agentes externos à comunidade e através de ações específicas), com o fornecimento do tratamento específico, muitas vezes, como única medida oferecida aos infectados e não reduzindo a prevalência da endemia em muitos municípios, onde foram aplicados até oito tratamentos específicos aos infectados pelo S. mansoni (Carmo \& Barreto, 1994).

Pesquisas operacionais sobre o controle da esquistossomose com abordagens alternativas têm sido preteridas pelas pesquisas sobre o tratamento específico, os métodos de diagnósticos e a prometida vacina (Kloetzel, 1992). Embora a estratégia da municipalização de programas de controle tenha propiciado bons resultados, a sua viabilidade exige estruturação no setor saúde, principalmente no repasse de recursos financeiros para o nível local, na capacitação técnica de recursos humanos locais, na organização da sociedade para exercer o controle fiscal dos recursos públicos e na definição dos papéis das instituições federais, estaduais e municipais (Coura-Filho et al., 1992). O desenvolvimento de abordagens al ternativas, incluindo-se aspectos das singularidades dos expostos à infecção pelo Schistosoma mansoni, torna-se um duplo desafio, por falta de metodologias de intervenção além do enfoque biológico e por não fazer parte da hegemonia bio-tecnológica já estabelecida no país por interesses médico-institucionais, onde o ato médico legitima a medicalização da doença e o papel interventivo do Estado (Luz, 1973).

\section{Abordagens alternativas}

A pesquisa participante (Borba, 1981), a “epidemiologia comunitária” (Tognoni, 1993), a educação popular (Valla et al., 1993) e, no caso da esquistossomose, o modelo de controle desta sugerido por Barbosa \& Coimbra (1992) e Barbosa (1993), aparecem como abordagens que visam à apreensão do indivíduo em sua globalidade, de forma a trazer seu universo simbólico-cultural, sua instrução histórica e sua "visão de mundo" e do processo Saúde/ Doença (S/D) para instrumentalizar a elaboração de uma prática de intervenção em saude pública de forma a reduzir o processo local de produção de doenças.

Conceitualmente, a pesquisa participante: “... é uma pesquisa da ação voltada para as necessi dades bási cas do indivíduo, responde especialmente às necessi dades de populações que compreendem operários, camponeses, agricultores eíndi os, classes mais carentes nas estruturas contemporâneas, levando em conta as suas aspi rações e potencial idades de conhecer e agi r. É uma metodologia que procura incentivar o desenvolvimento autônomo (autoconfiante) a partir das bases e uma relativa independência do exterior". (Borba, 1981:51)

Esta abordagem de pesquisa pressupõe que o pesquisador e a população estudada sejam sujeitos ativos no processo de transformação social, cabendo ao pesquisador e/ ou ao intelectual a função de facilitador comprometido com a produção de conhecimentos, tendo em vista a mudança da realidade.

No Brasil, esta abordagem teve início na década de 70. Tem como objetivo básico fornecer à população o conhecimento científico sobre áreas de interesse visando à resolução de problemas concretos percebidos e vividos, estimulando o uso da criatividade.

$\mathrm{Na}$ abordagem da pesquisa participante, surgiram dois tipos de prática: uma com compromisso partidário, “observação militante", e outra com base sócio-educativa, "investigação temática". A diferença básica entre elas é o partido na primeira e a definição do papel do intelectual na segunda. Entre elas identificam-se as seguintes características: a) objetivam a promoção e produção coletiva do conhecimento, b) desenvolvem a capacidade de análise crítica do indivíduo, c) promovem análise, incluindo as dimensões do coletivo e do individual, funcional e estrutural, de modo a encontrar soluções para problemas concretos da população.

No desenvolvimento da abordagem da pesquisa participante, algumas etapas são detectadas: a) identificação da equipe executora lo- 
cal, b) caracterização provisória da área ocupada pela população em estudo, c) diagnóstico visando à identificação dos problemas considerados prioritários conforme percepção da população, d) estabelecimento de programação conforme realidade e recursos locais, e) desenvolvimento do plano de ações, incluindo as educativas, dentro e fora do sistema formal de ensino, ef) avaliação e reprogramação das ações conforme resultados e deficiências do programa. Estas etapas devem ocorrer com intersecção entre elas, sem necessariamente torná-las cronologicamente lineares, de forma a garantir a participação das classes populares no processo de tomada de decisões em todas as fases da pesquisa.

A proposta da "epidemiologia comunitária" apresentada por Tognoni (1993) “é uma forma depensar epraticar a medicina". Tem seu objeto no sujeito comunitário. Seu objetivo é transformar a vida e as atividades cotidianas onde é produzida a doença. Comunidade e "operadores sanitários" buscam de forma crítica contornar progressivamente os problemas de saúde. Trata-se de uma capacitação da comunidade para atuar no seu meio de forma consciente.

Caminhos a serem seguidos na sua elaboração prática sugerem partir da "reali dade cotidiana" conforme percepção da própria comunidade, "instrumentalizar-se" por indicadores sensíveis que coloquem a realidade compreensível para a população e desenvolver uma "linguagem" decodificável que permita contextualizar os agravos de saúde.

Pressupõe ainda que o processo S/ D é generalizado e permeado pelo cotidiano; a saúde é uma manifestação do indivíduo, portanto carrega a especificidade do singular; embora a saúde ocorra com manifestação individual, ela é produzida por processos globais; é fundamental considerar o mosaico de situações, intervenções e indicadores presentes na diversidade do cotidiano; são etapas importantes o diagnóstico, as elaborações de programas, planejamentos e reavaliações de forma participativa entre comunidade e técnicos; deve-se considerar a produção de dados quantitativos como forma complementar para "fotografar a realidade"; a comunicação deve acontecer através de "informativo"; os mecanismos de avaliação e reprogramação devem ocorrer de forma crítica; a memória do mosaico de situações para auto referência é condição necessária na produção do conhecimento; seu objetivo maior é:

“... oferecer a todas las diversi dades el mismo estilo detrabalho, el mismo método, la misma capacidad de adopcion e de transparencia..." (Tognoni, 1993:34).
A educação popular proposta por Valla et al. (1993) tem como eixo principal a concepção de que o uso do dinheiro público na infra-estrutura para reprodução da vida deve ser garantido como direito do cidadão e não tem sentido pensar na educação popular sem infraestrutura material para tal.

Os programas oficiais para educação, saúde e outros serviços já têm contado com a participação popular, mas colocando o indivíduo como vítima e/ ou causa de sua condição de analfabeto, doente e pobre. Para reverter esta tendência, torna-se necessário: a) formar ou capacitar o indivíduo a se tornar cidadão; b) responsabilizar o Estado pela falta de "informação", que é a base para se buscar a "formação" de uma consciência coletiva externalizada em ações objetivas (neste sentido, torna-se estratégico a própria população criar seu banco de dados de forma a diagnosticar seus "problemas"); c) responsabilizar o Estado pela deseducação da população (por exemplo: recolher lixo desembalado é função do Estado e não da população; as propostas de educação tomam a Escola como referência, o que exclui crianças que estão fora do sistema educacional; as questões de educação para a saúde são de responsabilidade das Secretarias de Saúde; a educação tem sido uma prática ideológica do Estado, não referenciada na realidade do aluno).

A reversão deste tipo de abordagem, visando a fazer do indivíduo cidadão, consiste em "abrir as portas" da Escola e Centros de Saúde para intervenção popular; considerar que as Escolas e Centros de Saúde são públicos e que, portanto, a responsabilidade não é dos pais, mas do Estado; considerar também que os serviços de educação e saúde são direitos do cidadão. É apontada, ainda, a falta de decodificação entre técnicos e usuários dos serviços do Estado e sugere-se criar não só cursos em áreas específicas para uniformizar a informação, como também condições de participação. Estas abordagens, entre outras, são sugeridas com o objetivo de incluir o indivíduo no seu processo de educação popular contínuo, não perdendo de vista que só é possível construir o cidadão após oferecer condições materiais e, por isso, cobrando do Estado a responsabilidade de fornecer os meios.

\section{Aspectos antropológicos no controle da esquistossomose}

A abordagem antropológica no controle da esquistossomose proposta por Barbosa \& Coimbra (1992) considera a necessidade de se incluirem aspectos da subjetividade dos expos- 
tos à infecção. A fim de fazer algumas reflexões sobre a inclusão de alguns aspectos antropológicos no planejamento de programas de controle da esquistossomose e da inclusão da subjetividade na epidemiologia, serão relatadas algumas experiências vividas com populações em áreas endêmicas rurais.

Em Peri-Peri, M G, após dezesseis anos de programa de controle, eu procurava saber se o fornecimento de informações à população sobre a endemia seria uma medida a ser adotada na vigilância epidemiológica. Ao entrevistar um agricultor aposentado residente na área, que estava fazendo um balaio para pescar, objetivando saber seo mesmo tinha conhecimento de como infectar-se pelo S. mansoni, ele respondeu:
“Dr., eu sei que na água tem o caramujo e que dentro dele tem a "xistose", mas quando eu vejo os peixinhos n' água minha perna coça, e muito mais, ése eu não entrar lá com o balaio pra pegar os peixes". "Pedro Azulão" (63 anos, Capim Branco, MG).

Nesta área, observamos que a população respondeu corretamente entre 44,8 e $93,1 \%$ das perguntas sobre $o$ agente infeccioso, como se infecta, quais os sinais e sintomas, localização do verme no corpo, como se faz o diagnóstico, como tratar, que danos à saúde são provocados pela endemia e quais as medidas preventivas que são necessárias para se evitar a infecção. Ou seja, nesta área, a falta de informações não estava associada à infecção (Tabela 1).

Tabela 1

Conhecimento sobre a esquistossomose dos indivíduos maiores de sete anos no Distrito de Peri-Peri (Capim Branco, $M G$ ), após dezesseis anos de programa de controle da endemia.

\begin{tabular}{|c|c|c|c|}
\hline $\begin{array}{l}\text { Conhecimentos } \\
\text { sobre: }\end{array}$ & $\begin{array}{l}\text { Infectados * } \\
(n=29) \%\end{array}$ & $\begin{array}{l}\text { Não-infectados } \\
(n=79) \%\end{array}$ & $\begin{array}{l}\text { Odds-ratio } \\
\text { (IC a 95\%) }\end{array}$ \\
\hline \multicolumn{4}{|c|}{ a) Se sabe que: a doença é provocada por verme? } \\
\hline sabia & (20) 69,0 & (53) 67,1 & 1,00 (referência) \\
\hline $\begin{array}{l}\text { não sabia } \\
p^{\prime}=0,9623\end{array}$ & (09) 31,0 & (26) 32,9 & $1,09(0,40-3,01)$ \\
\hline \multicolumn{4}{|c|}{ b) Q ue a infecção é adquirida por contato com águas naturais? ** } \\
\hline sabia & (09) 31,0 & (09) 11,4 & 1,00 \\
\hline $\begin{array}{l}\text { não sabia } \\
p^{\prime}=0,0327\end{array}$ & (20) 69,0 & (70) 86,6 & $3,50(1,09-11,32) * * *$ \\
\hline \multicolumn{4}{|c|}{ c) Q uais são os sinais e/ou sintomas? } \\
\hline sabia & (16) 55,2 & (33) 41,7 & 1,00 \\
\hline $\begin{array}{l}\text { não sabia } \\
\mathrm{p}^{\prime}=0,3069\end{array}$ & (13) 44,8 & (46) 58,3 & $1,72(0,67-4,42)$ \\
\hline \multicolumn{4}{|c|}{ d) Onde é a localização do verme no corpo? } \\
\hline sabia & (15) 51,7 & (50) 63,3 & 1,00 \\
\hline $\begin{array}{l}\text { não sabia } \\
\mathrm{p}^{\prime}=0,3862\end{array}$ & (14) 48,3 & (29) 36,7 & $0,62(0,24-1,60)$ \\
\hline \multicolumn{4}{|c|}{ e) Como se faz o diagnóstico? } \\
\hline sabia & (20) 69,0 & (43) 54,4 & 1,00 \\
\hline $\begin{array}{l}\text { não sabia } \\
p^{\prime}=0,2552\end{array}$ & (09) 31,0 & (36) 45,6 & $1,86 \quad(0,69-5,07)$ \\
\hline \multicolumn{4}{|c|}{ f) Como se faz o tratamento? } \\
\hline sabia & (20) 69,0 & (56) 76,9 & 1,00 \\
\hline $\begin{array}{l}\text { não sabia } \\
p^{\prime}=0,9649\end{array}$ & (09) 31,0 & (23) 29,1 & $0,91 \quad(0,33-2,55)$ \\
\hline \multicolumn{4}{|c|}{ g) Como se previnir contra a doença? } \\
\hline sabia & (27) 93,1 & (68) 86,0 & 1,00 \\
\hline $\begin{array}{l}\text { não sabia } \\
p^{\prime}=0,2631\end{array}$ & (02) 6,9 & (11) 13,9 & $2,18 \quad(0,41-15,32)$ \\
\hline \multicolumn{4}{|c|}{ h) Por que algumas pessoas pegam a doença e outras não? } \\
\hline sabia & (08) 27,6 & (28) 35,4 & 1,00 \\
\hline resistência **** & (08) 27,6 & (20) 25,3 & $1,12 \quad(0,39-3,22)$ \\
\hline $\begin{array}{l}\text { contato } c / \text { água } \\
\mathrm{p}^{\prime}=0,7417\end{array}$ & (13) 44,8 & (31) 39,3 & $1,26 \quad(0,49-3,24)$ \\
\hline
\end{tabular}

$p^{\prime}$ valor de qui-quadrado com correção de Yates

* com ovos de S. mansoni; ** $\mathrm{p} \leq 0,05 ;{ }^{* * *}$ de córregos, minas, rios, etc; **** imunológica. 
Representação semel hante foi emitida por uma dona de casa em Comercinho, MG. Interrogada se sabia que no córrego onde estava lavando vasilhas e dando banho nas crianças tinha caramujo da "xistose", ela respondeu:

“...sim, eu sei que nestas terras tem "xistose" mas tenho que mandar a comida para o marido na roça até as dez horas da manhã... ...meu avô e meu pai morreram de "barriga d'água" quando já estavam de cabeça branca... (e, muito séria disse) .... fome "nestas bandas" mata mais que a "xistose". Lavadeira (33 anos, Comercinho, $\mathrm{MG}$ ).

Ou seja, oferecer informações sobre a transmissão da esquistossomose a esta lavadeira não foi o suficiente para que evitasse o contato com águas contendo cercárias de S. mansoni. Isto é, a informação sem fornecer os meios não foi suficiente para se tornar potência em ação de prevenção e/ ou controle da endemia nestas áreas.

Buscando incluir o subjetivo na epidemiologia

O uso de métodos epidemiológicos clássicos (ambiental e social) não deram conta de solucionar todos os problemas de saúde produzidos pelo sistema capitalista (Almeida Filho, 1990), mas não devem simplesmente ser abandonados por não dar conta do todo. Qualquer método novo da epidemiologia que tentar pensar e compreender a complexidade do todo não pode negar a produção de conhecimentos descritivos e explicativos produzidos pelos métodos de identificação de determinantes imediatos de doenças.

Estando a subjetividade (Guattari, 1990) e/ ou singularidade (Castellanos, 1987) incluídas no cotidiano, elas não podem se tornar objeto de uma prática que possa alterar sua realidade sem a construção da cidadania e a consciência do seu papel ativo na construção do real. Qualquer ciência não consegue interferir e resolver todas questões do real (Castiel, 1994). Entender a complexidade da doença na sua instabilidade constante, na sua irracionalidade pressupõe incluir o universo do singular: subjetivo, simbólico, irracional, teológico e mitológico.

Entrevistando um comerciante visando captar a representação da população de Comercinho, MG, sobre a esquistossomose e o programa de controle que estava sendo desenvolvido na sede do Município, após a pergunta “Para você, o que é esquistossomose?", ele respondeu:
“Eu tenho. A minha esquisitosemóvel morde por dentro. Tem dia que morde assim pela barriga atéas costas, tem hora queformiga a perna toda, e vai roendo a gente todo por dentro". Comerciante (45 anos, Comercinho, MG).

Para este indivíduo, a endemia era provocada por um verme grande que andava pelo corpo todo comendo-o por dentro, na barriga, cabeça e pernas.

Na tribo dos Machacalis, MG, foi desenvolvido um programa de controle de verminoses. Após o primeiro dia de administração da droga anti-helmíntica em um grupo de infectados, o cacique da tribo não queria mais permitir a continuidade do tratamento porque:

“...o comprimido está virando vermena barriga" Cacique dos Machacalis, MG.

Após o tratamento, vermes adultos de Ascaris lumbricoides eram eliminados vivos nas fezes, e para o cacique eram os comprimidos que haviam se transformado em vermes.

Em Tuparecê, M G, um ano após o fornecimento de Mansil para tratamento dos infectados, observamos que apenas $30 \%$ dos que receberam a droga para tomar em casa haviam levado a cabo o tratamento. Verificamos posteriormente que uma matriarca da região, grande proprietária de terras, havia tomado sua dose de Mansil e sentiu tonteira. I mediatamente mandou avisar a população para:

“não tomar o remédio da xistose porque é perigoso" Fazendeira mineira (58 anos, Tuparecê, MG, Médio Jequitinhonha).

Desenvolvendo um programa de controle da endemia em Taquaraçu de Minas, MG, com participação popular nas ações de educação para a saúde, deparei com um cartaz pregado na porta de um pequeno armazém, feito por uma aluna da 3ạ série primária, com os seguintes dizeres:

"Senhor

Dai-me a esperança para vencer a Esquistossomose

Plantai em nossos corações a sementei ra da inteligência;

E ajudai-me a fazer feliz o maior número da humanidade possível;

Dai-me o sabor de saber vencer e afastar de todos nós a Esquistossomose.

Senhor,

Iluminai os olhos do povo para quese prote jam contra doenças.

Senhor,

Levai do mundo a Esquistossomose, enão a entregueis a mundo nenhum.

Enchei os nossos corações com a divina fé de que, li vraremos rápi do desta doença, e arrancai denós o orgulho ea insegurança. 
Deus,

Fazei de todos nós homens e (mulheres), realmentejuntos para queo amanhã não exista coisas ruins." Estudante (13 anos, Taquaraçu de Minas, MG).

Para esta aluna, a falta de material didático e a impotência diante do problema fez com que colocasse o controle da esquistossomose nas mãos de Deus. Pensamento religioso e/ ou mágico semelhante foi identificado em uma dona de casa desta mesma comunidade. Quando Ihe foi perguntado se sabia como tratar a esquistossomose, afirmou:

"Bom pra curar a "xistose" é dar banho em água com sangue detatu canastra....... precisa de remédio não" Dona de casa (idade desconhecida, Taquaraçu de Minas).

Tempos depois, pude observar o quanto a carne do animal é vermelha. Concluí que esta senhora sugeria "curar" a anemia provocada por vermes com a hemoglobina livre das hemácias lisadas na água onde era lavada a carne do animal.

\section{Discussão}

Estas são algumas representações identificadas em populações de áreas endêmicas que foram trabal hadas com a finalidade de vencer a resistência de indivíduos para receber o tratamento adequado e que, em programas com participação popular, podem ser encontradas facilmente.

A construção do conceito de saúde/ doença pelos usuários são fragmentos introjetados formados com informações científicas que sofrem uma recomposição, incluindo-se aspectos subjetivos, culturais, fantasias e pensamentos mágicos, que nem por isto deixam de ser reais para quem os constrói, mas que necessariamente devem ser decodificados pelos agentes sanitários em prestação de serviços, para se estabelecer uma linguagem capaz de permitir contato.

Como se percebe, o racional, como instrumento que pode vir da inclusão do subjetivo na epidemiologia, pode não se tornar científico como entendido nas ciências duras, mas necessariamente está e sempre esteve no cotidiano. Não é pelo fato de a ciência apenas explicar e não ser capaz de organizar a realidade humana na sua totalidade que o singular não é objeto de produção de conhecimento (Castiel, 1994). Talvez os model os epidemiológicos até então desenvolvidos para descrever a evolução natural das doenças e para explicar sua ocorrência sejam acumulações necessárias à formulação de um modelo que, além de descrever e explicar, venha propor ações que alterem a realidade bio-social de produção de doenças (Coura-Filho, 1994).

Uma abordagem com enfoque antropológico, visando ao controle da esquistossomose, que considere a forma de organização social dos expostos deve necessariamente incluir o indivíduo singular. Neste sentido, a formulação teórica da organização social do espaço de SMITH (1988), como sendo a natureza criada socialmente, exige a compreensão do indivíduo que a cria, por que a cria e como a cria. Sua formulação teórica de que o sujeito cria a natureza quando a representa pressupõe a presença do indivíduo ativo, vítima e produto do tipo de interação que mantém e reproduz o espaço.

Todo indivíduo tem na sociedade o lugar de reprodução da vida. A construção do conceito coletivo contemplando a singularidade só é possível através da inter-relação de organismos coletivos. A elaboração do conceito de saúde coletiva, fundamental para atender processos de produção de doenças (Gawryszewski, 1993), apresenta-nos dificuldades para inclusão do subjetivo. A externalidade das relações singulares é de natureza diferente do singular unitário, produz enunciados de subjetivação col etiva (Guattari, 1990).

Se considerarmos que a subjetividade é objeto de interesse do capital, tão importante quanto foi a mercadoria e atualmente é o controle da informação e os bens de serviços, podemos perceber que a subjetividade não pode ser mais negada como parte do real apenas por não ser operacional nos serviços de saúde.

A massificação da subjetividade via efeito demonstração da propaganda, estrategicamente construída pela necessidade de sobrevivência do capital, acaba produzindo alienação em massa em indivíduos sem identidade de cidadão que se tornam "objeto de manobra" do processo de acumulação desigual do capital (Coura-Filho, 1996).

Mas, como sobrevive esta biomassa sem identidade? Ela não se dissiparia sem qualquer tipo de identidade? Se existe algum tipo ou fragmento de identidade, qual sua origem? Ela é construída também pelo interesse do capital? O desejo do indivíduo do circuito inferior seria simplesmente chegar ao circuito superior (Santos, 1978)? E sua história? Sua cultura? Seria arquivo morto?

Uma observação cuidadosa em sociedades autônomas, nas mais conservadoras como em Minas Gerais e/ou em reservas indígenas, aponta a presença da solidariedade no circuito inferior como um mecanismo modulador da 
dissipação, além da reprodução simples e/ou acumulação de biomassa. Esta solidariedade não teria em si o conteúdo da representação coletiva como possibilidade de (re)construção de uma identidade social? Uma das representações arquetípicas, portanto inconsciente, que tem funcionado como expressão de resistência do circuito inferior, ocorre também através da cultura? Esta, quando organizada, poderia se tornar potência capaz de alterar a realidade cotidiana de excluídos? O uso do referencial teórico da pesquisa participante, da “epidemiologia comunitária" e da educação popular, centrado nas inter-relações de singularidades, pode se tornar potência para ações no planejamento, execução e avaliação de programas de controle de $70 \%$ das doenças que têm veiculação hídrica e, portanto, são sócio-dependentes, como a esquistossomose?

\section{Referências}

ALMEIDA-FILHO, N., 1990. A Clínica ea Epidemiologia. Rio de Janeiro: APCE-ABRASCO.

BARBOSA, F. S., 1993. Aspectos sócio-econômicas e participação da comunidade na determinação e controle da esquistossomose. In.: IV Simpósio Internacional de Esquistossomose (A. L. T. Rabelo; A. Gonçalves; C. M. S. D. Da Silva; M. Siriani \& R. S. Rocha, orgs). Rio de Janeiro: CIA Brasileira de Arte.

BARBOSA, F. S. \& COIM BRA Jr., C.E.A.,1992. Alternative approaches in schistosomiasis control. Memórias do Instituto Oswal do Cruz, 4:215-220.

BARBOSA, F. S.; PINTO, R. \& SOUZA, O., 1971. Control of schistosomiasis in a small northeast Brazilian community. Transactions of the Royal Society of Tropical Mededicineand Hygiene, 65:206-213.

BARRETO, A. C. \& PRATA, A., 1969. Aplicação em massa de moluscicida pela população local em uma área endêmica de esquistossomose. Gazeta Medica da Bahia, 69:20-24.

BORBA, O. F., 1981. Aspectos teóricos da pesquisa participante. In.: Repensando a Pesquisa Participante (C. R. Brandão, org), pp. 42-62, São Paulo: Brasiliense.

CARM O, E. H. \& BARRETO, M. L., 1994. Esquistossomose mansônica no Estado da Bahia, Brasil: tendências históricas e medidas de controle. Cadernos de Saúde Pública, 10:425-439.

CASTELLANOS, P. Z., 1987. Sobre el Concepto de Salud - Enfermidad: Un Ponto deVista Epidemiológico. I Taller Latino-Americano de Medicina Social, Medelin. (mimeo.)

CASTIEL, L. D., 1994. O Buraco e o Avestruz - A Singularidade do Adoecer Humano. Campinas: Papirus.

COURA-FILHO, P., 1994. Uso do paradigma de risco para a esquistossomose em áreas endêmicas no Brasil. Cadernos de Saúde Pública, 10:464-472.

COURA-FILHO, P., 1996. Distribuição da esquistossomose no espaço urbano. II aproximação teórica sobre a acumulação, concentração, centralização

\section{Agradecimentos}

Aos Profs. Luis David Castiel e Frederico Simões Barbosa pelas colaborações na revisão e pelas valiosas sugestões na elaboração deste artigo. À Dra. Elizabeth Uchôa pelas observações sobre aspectos antropológicos considerados na elaboração deste artigo, que, com certeza, servirão como importante material a ser continuamente elaborado ao longo de nossa constante formação. do capital e a produção de doenças no espaço urbano. Cadernos de Saúde Pública (no prelo).

COURA-FILHO, P.; ROCHA, R. S.; LIMA E COSTA, M. F. F. \& KATZ, N., 1992. A municipal level approach to the management of schistosomiasis control in Peri-Peri, MG, Brazil. Revista do Instituto de Me dicina Tropical deSão Paulo, 43:543-548.

GAWRYSZEWSKI, V., 1993. Regionalização dos serviços de saúde: al gumas considerações acerca da relação entre a descentralização, autonomia local e a participação do cidadão. Cadernos de Saúde Pública, 9:210-215.

GUATTARI, F., 1990. Caosmose. Rio de Janeiro: Ed. 34.

KLOETZEL, K., 1992. Ciência auto-sustentada: o caso da esquistossomose. Cadernos de Saúde Pública, 8:204-206

LUZ, T. M., 1973. As Instituições Médicas no Brasil. Rio de Janeiro: Ed. Graal.

PECE (PROGRAMA ESPECIAL DE CONTROLE DA ESQUISTOSSOM OSE), 1976. Publicações do Conselho de Desenvolvimento Social. Brasília. (mimeo.)

SANTOS, M., 1978. Os dois circuitos da economia urbana dos países subdesenvolvidos. In.: O Espaço Dividido (M. Santos, org), pp. 21-64, Rio de Janeiro: Livraria Francisco Alves.

SMITH, N., 1988. Desenvolvimento Desigual: Natureza, Capital e a Produção do Espaço. Rio de Janeiro: Bertrand Brasil.

TOGNONI, 1993. Epidemiologia comunitária. Apuntes para una nueva epidemiologia. Salud y Sociedad, 10:4-10.

VALLA, V. V.; CARNEIRO, C. \& ASSIS, M., 1993. Partici pação Popular e os Serviços de Saúde: O Controle Social como Exercício de Cidadania. Rio de Janeiro: Ed. PARES/ENSP/Fiocruz.

OMS (ORGANIZAÇÃO MUNDIAL DE SAÚDE), 1985. Report of a WHO expert communittee, Geneve. The Control of Schistosomiasis. Geneve. (mimeo.) 